$R R-75-20$

\title{
STORAGE SYSTEMS DEPENDENT ON MULTIVARIATE STOCHASTIC PROCESSES
}

Z. Kaczmarek

July 1975

Research Reports are publications reporting on the work of the author. Any views or conclusions are those of the author, and do not necessarily reflect those of IIASA. 



\section{Storage Systems Dependent on Multivariate}

\section{Stochastic Processes}

Z. Kaczmarek

\section{Introduction}

The theory of storage appears to provide a suitable basis for a general analysis of water resources systems. Dooge [4], Nash [16] and others have described the watershed by a system of storages; Kirby [10] presented the hydrologic cycle as a network (Figure 1) of storage processes, each acting deterministically on a random input. The most obvious example of the importance of storage theory in water resources is furnished by a system of reservoirs (Figure 2) constructed for meeting some water needs and/or for preventing flood damages. The theory of cooling ponds and lakes may also be based on the analysis of storage of waste heat from thermal power plants (Figure 3).

Most of the papers on storage theory were done in the spirit of one-dimensional stochastic processes. Moran [15] in his pioneer work found the probability distribution of water stored $v_{i}(i=1,2, \ldots)$, assuming the inflows $Q_{i}$ to be independent and form the stationary random process. Kaczmarek [8] and Lloyd [11] used different methods for extending Moran's model to the case of correlated inflows. Anis [2], Gani [5], Rozanov [18], Prabhu [17] and others contributed significantly to the stochastic storage theory. 


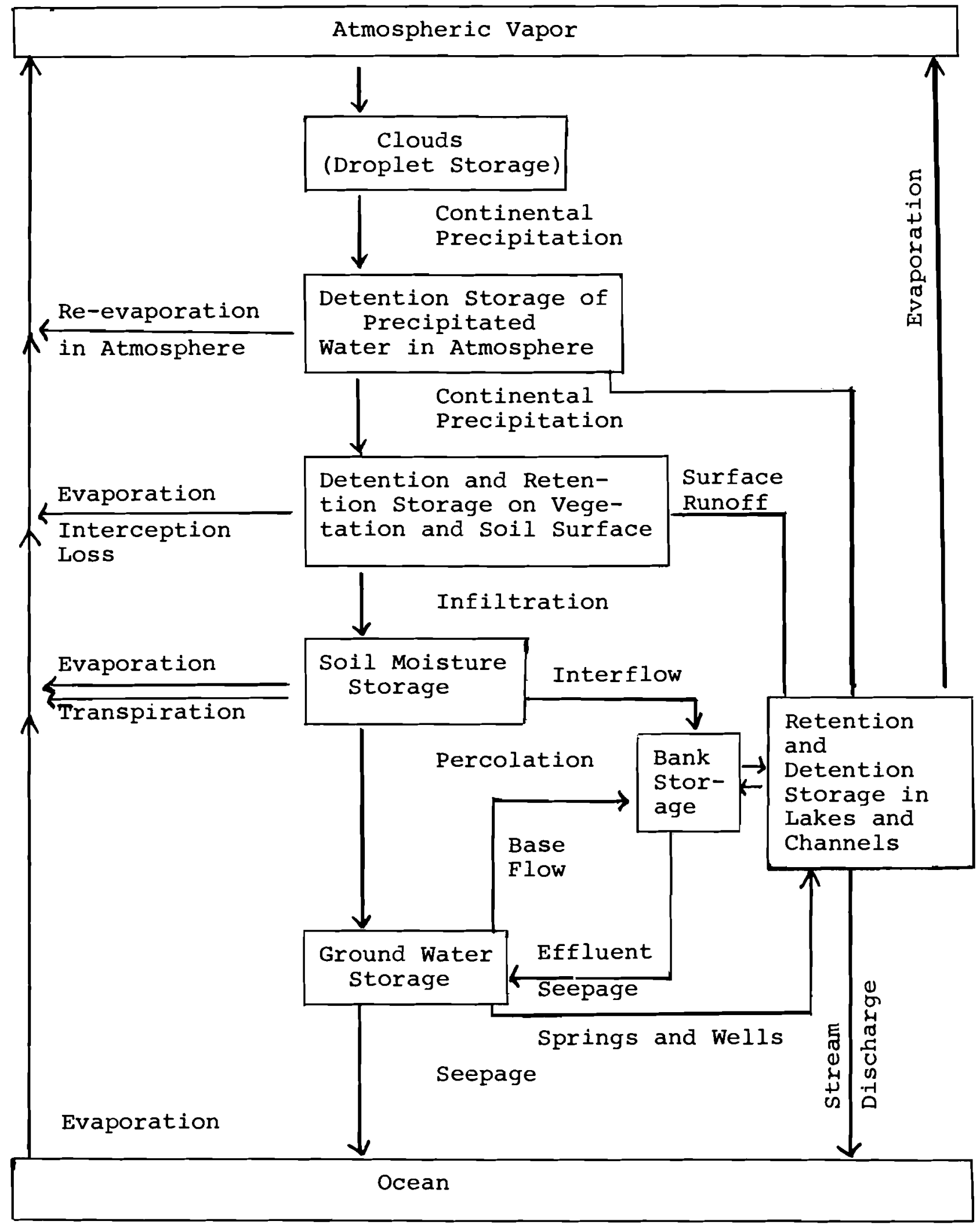

Figure 1

Continental phase of the hydrologic

Cycle (After Kirby (10)) 


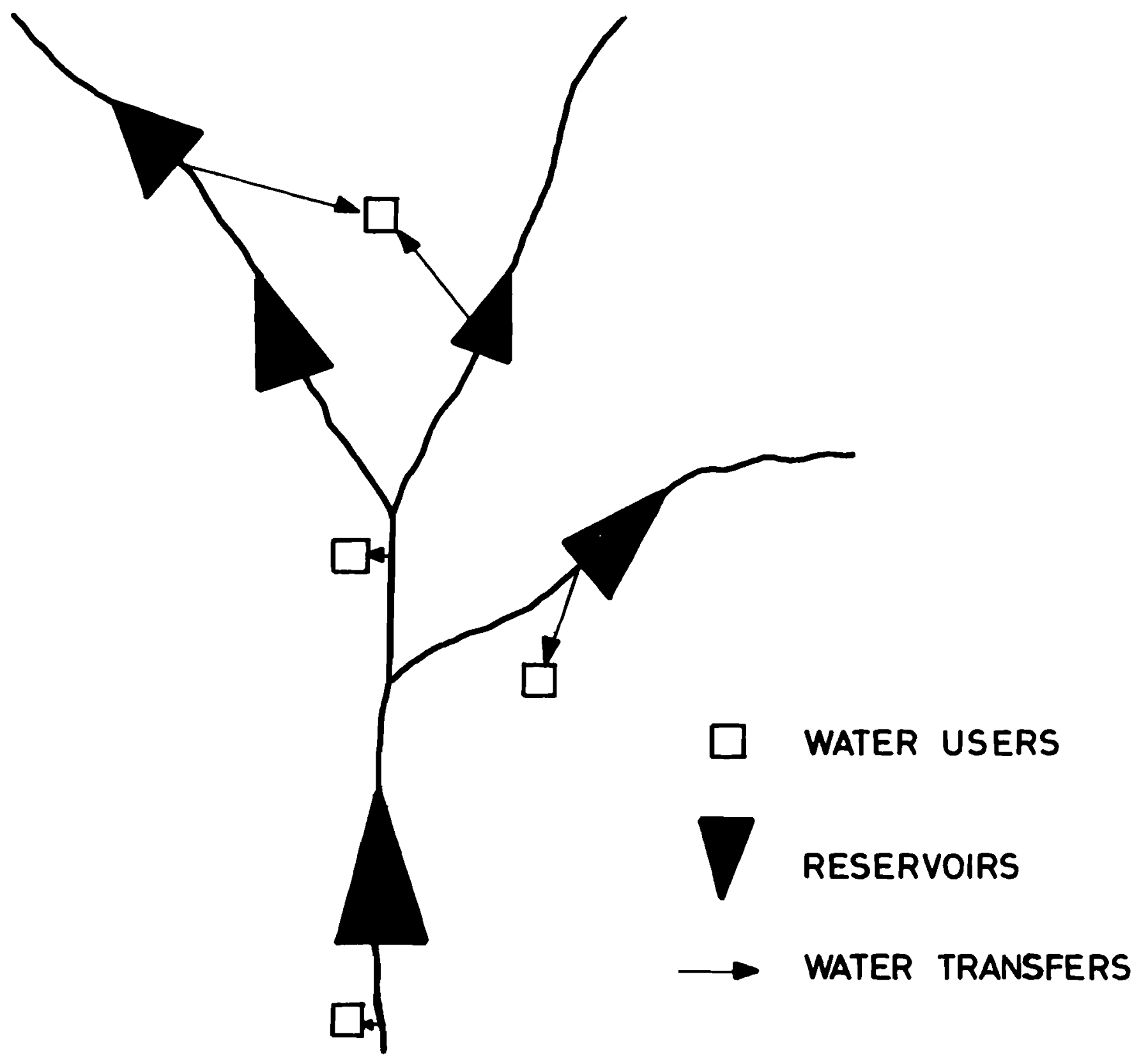

FIGURE 2. THE SYSTEM OF RESERVOIRS. 


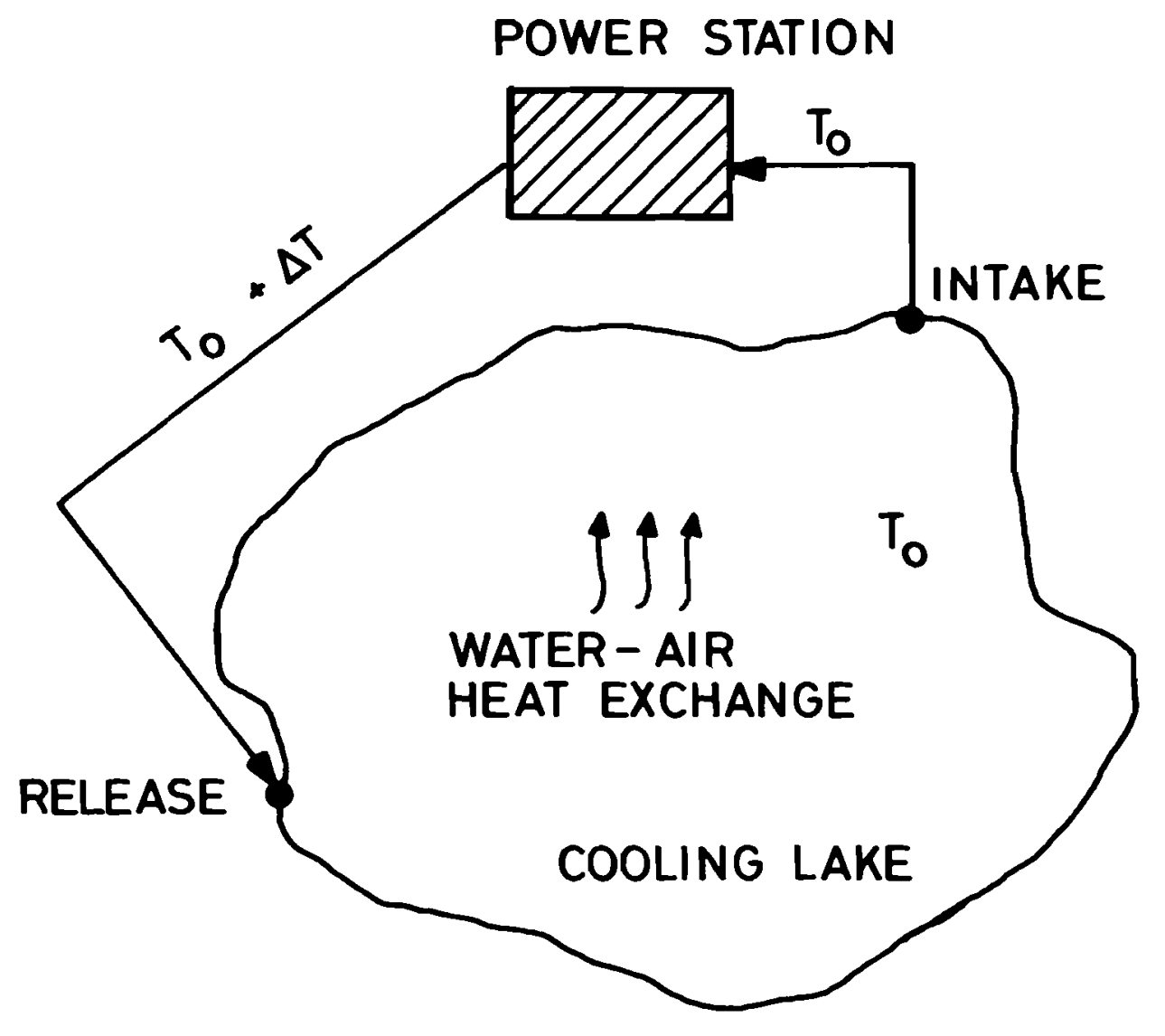

FIGURE 3. COOLING LAKE AS A STORAGE SYSTEM. 
However, in many cases the storage process depends on the random vector inputs and outputs. Let us mention only two simple examples.

1. The stochastic behavior of the reservoir storage levels may usually be described by the simple differential equation

$$
W \frac{d \zeta}{d t}=Q(t)-Q_{0}(t)
$$

where

$$
\begin{aligned}
W: \text { maximum capacity of the reservoir (cu.m.), } \\
\zeta(t)=\frac{V(t)}{W}: \text { relative storage level, } \\
Q(t): \text { inflow to the reservoir }(\mathrm{cu.m.} / \mathrm{sec}), \\
Q_{0}(t): \text { outflow from the reservoir }(\mathrm{cu} . \mathrm{m} . / \mathrm{sec}) .
\end{aligned}
$$

In [7] the following operation (release) rule was proposed for the outflow from the reservoir, supplying water to certain users:

$$
Q_{O}(t)=D(t)\left[1-\frac{0,01}{\zeta(t)}\right]+Q(t) \cdot \frac{0,01}{1-\zeta(t)},
$$

where $D(t)$ is the water demand. It is obvious that using (2) the storage level will always fulfill

$$
0<v(t)<w
$$

Substituting (2) into (1) we obtain the nonlinear differential equation

$$
\frac{d \zeta(t)}{d t}=\frac{1}{W}\left[Q(t)\left[1-\frac{0,01}{1-\zeta(t)}\right]-D(t)\left[1-\frac{0,01}{\zeta(t)}\right]\right] \text {. }
$$

In many cases, e.g. for the agricultural water supply, $D(t)$ 
is a random process, usually highly correlated with $Q(t)$. Consequently, the storage process $\zeta(t)$ is formed by the random vector $\langle Q(t), D(t)\rangle$.

2. In [6] Jurak proposed the following equation for the water-air energy exchange from cooling lakes:

$$
Q_{C}=\alpha_{0}+\alpha_{1} T_{0}+\alpha_{2} T_{0}^{2},
$$

where

$Q_{C}:$ the rate of energy exchange $\left(\mathrm{cal} / \mathrm{cm}^{2}, \mathrm{~h}\right)$,

$T_{0}$ : the surface water temperature $\left({ }^{\circ} \mathrm{C}\right)$,

$\alpha_{i}=\phi_{i}\left(u, T, e, Q_{s r}, \ldots\right):$ the random coefficients dependent on the wind velocity $u$, air temperature $T$, water vapor $e$, short-wave radiation $Q_{s r}$ and other meteorological phenomena.

Assuming the full mixed cooling lake (pond), the following differential equation describes the water temperature changes in the impoundment, provided the body of water is assumed to have uniform temperature distribution

$$
\frac{\mathrm{dT}}{\mathrm{dt}}=\frac{1}{\rho c_{w} V}\left(\alpha_{0}+L+\alpha_{1} \mathrm{~T}_{0}+\alpha_{2} \mathrm{~T}_{0}^{2}\right),
$$

where

$$
\begin{aligned}
& \rho: \text { water density, } \\
& c_{w}: \text { specific heat of the water, } \\
& V: \text { volume of water in the impoundment, } \\
& L: \text { thermal load. }
\end{aligned}
$$

Obviously the stochastic process $T_{0}(t)$ depends on the random vector $\left\langle\alpha_{0}, \alpha_{1}, \alpha_{2}\right\rangle$, assuming that $V$ and $L$ are constant or change deterministically. 
The purpose of this paper is to present some of the results described earlier [8] for the case of univariant input processes and to extend them to the multivariate case.

\section{Reservoir Dependent on Univariate Stochastic Input}

Let us consider a reservoir such that the volume $v(t)$ of water stored, during any time period, is

$$
0<V(t)<W .
$$

The maximum usable capacity $B$ may be either constant or variable in time, e.g. it may be different during the flood and drought periods. Assuming the constant (average) inflow $Q_{i}$ in the period $\left(t_{i-1}, t_{i}\right)$, we obtain from (1)

$$
W \frac{d \zeta(t)}{d t}=Q_{i}-Q_{0}(t), t_{i-1}<t<t_{i} \text {. }
$$

Should the storage model serve for solving some real water resources problems, a number of specific requirements has to be met. In particular:

- the reservoir volume must be finite,

- the inflow model should describe realistically the relevant hydrologic phenomena, i.e. the input $Q_{i}$ being nonnegative, usually time dependent, seasonally distributed, stationary (at least in many cases) with respect to annual series, and having a skewed probability distribution,

- the function describing the operating (release) rules should reflect the system's objectives, be valid also for 
extreme hydrologic conditions of floods and droughts, be realizable by the dispatcher and, in particular, be based on the currently available information. Incidentally, it should be stressed that a large number of interesting papers are available in the mathematical literature devoted to the "dam theory", which do not satisfy the above conditions. The aim of those papers was to develop mathematics, and, of course, water resources scientists and engineers should not expect mathematicians to be very much interested in the consistency of their assumptions with the real world water resources problems. Instead of complaining, water resources specialists should either sensibly adapt the existing mathematical knowledge (when feasible), or develop--in cooperation with mathematicians--the theory based on more realistic assumptions.

To return to the main subject, we should now discuss in some detail the possible operating rules for $Q_{0}(t)$. In most practical cases the output (release) discharge can be presented as a function of the current storage level, reservoir inflow and a number of deterministic parameters

$$
Q_{0}(t)=\phi\left(\zeta(t), Q_{i}, C_{1}, C_{2}, \ldots\right)
$$

Let us confine ourselves to a class of functions (9) which, substituted into (8) and after integration, give the functional relationship

$$
\zeta\left(t_{i}\right)=g\left[\zeta\left(t_{i-1}\right), Q_{i}, c_{1}, c_{2}, \ldots\right]
$$


for which also the unique inverse transformation

$$
Q_{i}=h\left[\zeta\left(t_{i-1}\right), \zeta\left(t_{i}\right), c_{1}, c_{2}, \ldots\right]
$$

exists for all $\zeta\left(t_{i-1}\right), \zeta\left(t_{i}\right)$ and for all values of parameters.

Let us now assume that $Q_{i}(i=1,2,3, \ldots)$ is the $1 \mathrm{ag}-\mathrm{m}$ time-discrete Markov process. It is obvious [1,7] that if $(10)-(11)$ are valid, the process $\zeta_{0}=\zeta\left(t_{0}\right), \zeta_{1}=\zeta\left(t_{1}\right), \ldots$, $\zeta_{i}=\zeta\left(t_{i}\right), \ldots$ is the lag- $(m+1)$ time-discrete Markov process. If for example $m=1$, the process $\zeta_{i}$ is the lag-two process and the bivariate $\left\langle\zeta_{i-1}, \zeta_{i}\right\rangle$ is again the simple (lagone) Markov process. However, it should be remembered that the Markov property will be lost if there is no unique relationship between the states of the original and the transformed processes.

Let us take for example the release function (2), but assuming the constant (non-random) demand $D(t)=d$ (Figure 4). After integrating (4) we obtain

$$
\Phi\left(\zeta_{i}\right)=\Phi\left(\zeta_{i-1}\right)+\frac{t_{i}-t_{i-1}}{w}
$$

where

$$
\begin{aligned}
\Phi(\zeta) & =-\frac{\zeta}{c}+\frac{1}{2 c}\left(1+\frac{c}{b}\right) \ln \left(a+b \phi+c \zeta^{2}\right)+ \\
& +\frac{1}{2 c}\left(b+\frac{b^{2}-2 a c}{c}\right) \frac{1}{\sqrt{\Delta}} \ln \frac{b+2 c \zeta+\sqrt{\Delta}}{-b-2 c \zeta+\sqrt{\Delta}},
\end{aligned}
$$

with $a=0.01 d, b=0.99 Q_{i}-1.01 d, c=d-Q_{i}$. 


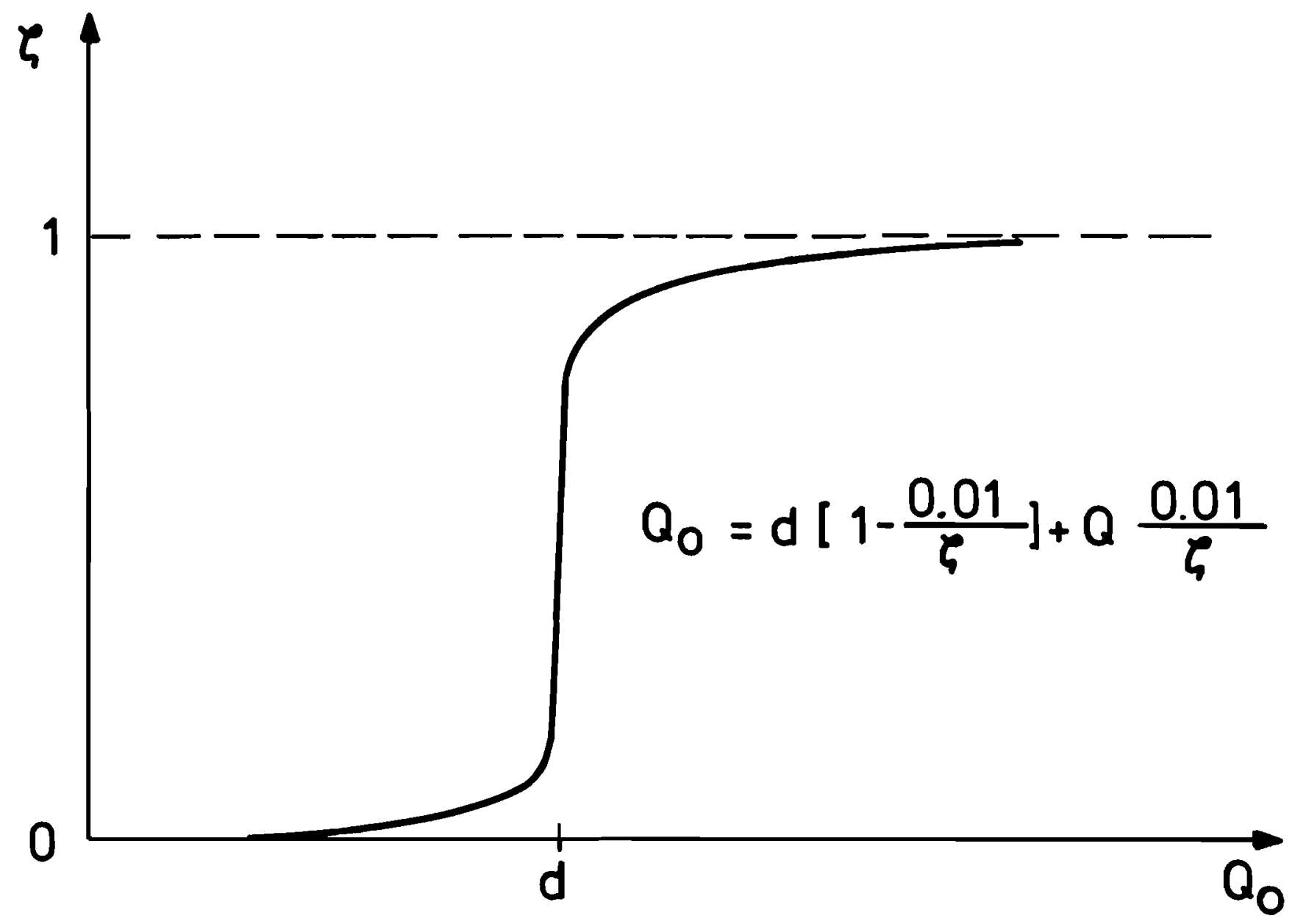

FIGURE 4.RESERVOIR RELEASE RULE AN EXAMPLE. 
It is clear that for given $\left(\zeta_{i-1}, \zeta_{i}\right)$ and given $\alpha, \beta, t_{i-1}, t_{i}$ we may obtain the unique value of $Q_{i}$. The given realization of the process $\zeta(t)$

$$
\begin{array}{ll}
\zeta_{\mathrm{m}}=z_{\mathrm{m}}, & \zeta_{\mathrm{m}-1}=z_{\mathrm{m}-1}, \ldots, \quad \zeta_{i}=z_{i}, \ldots \\
\zeta_{1}=z_{1}, & \zeta_{0}=z_{0}
\end{array}
$$

determines the trajectory

$$
\mathrm{Q}_{\mathrm{m}}=\mathrm{q}_{\mathrm{m}}, \quad \mathrm{Q}_{\mathrm{m}-1}=\mathrm{q}_{\mathrm{m}-1}, \ldots, \quad \mathrm{Q}_{1}=\mathrm{q}_{1}
$$

of the process $Q_{i}$. So, if $Q_{i}$ is the simple Markov process, then $\zeta\left(t_{i}\right)$ is also Markovian, but with lag $m=2$.

The computational procedures for finding the probabilistic structure of the above reservoir process are described in [8] and will not be repeated here. The approximate solution may be obtained by dividing the $\zeta$-space into $r$ states (intervals). The errors in discretization may be reduced by using a large number of small intervals, although it should be remembered that the resulting matrices (for each time interval $\Delta t=t_{i}-t_{i-1}$ ) have $r^{4}$ elements for $m=2$. Similar computational difficulties arise when using the Lloyd theory of reservoirs with correlated inflows.

Let us add a few more comments concerning the univariate case. As we mentioned before, the inflows to the reservoir should be periodic (seasonally distributed). It may also be assumed that the release function is again periodical, so it has exactly the same shape for $t, t+T, t+2 T, \ldots$ where $T$ is the period of one year. It may be shown that under 
very general assumptions the ergodic probabilities of the resulting storage process are also periodic. Interesting results in the theory of statistical equilibrium of storage processes were recently published by Rozanov [18] . However, it should be stressed that for operational purposes the water resources manager may be more interested in the current probability structure of the storage process, i.e. in the first few matrices $A_{1}, A_{2}, \ldots, A_{j}, \ldots$, where

$$
A_{i}=\left\langle P_{i, j}=P\left[v_{i}\left(t_{j}\right)\right]\right\rangle,
$$

assuming that the initial storage conditions

$$
v\left(t_{0}\right)=v \text { for } t=t_{0}
$$

are given. The reservoir dispatcher may then evaluate the possible results, expressed in probabilistic terms, of using the given operational policy, or may compare the effects of applying different policies. Mitosek [13] combined the storage model and the dynamic programming approach to find the optimal operational rules for a single reservoir. It should also be observed that when using storage models for operational purposes, the conditional (i.e. forecast) probability distribution of inflows

$$
f_{\text {cond }}\left(Q_{1}, Q_{2}, Q_{3}, \ldots \ldots \mid z_{1}, z_{2}, \ldots, z_{r}\right)
$$

can be applied, where $z_{i}$ denotes given predictors, that is, hydrometeorological factors affecting the probability distribution describing the inflow process to the reservoir. The general theory and type of hydrologic forecasting was presented in [ 9 ]. 


\section{Multivariate Stochastic Input to storage systems}

Let us consider the dynamic storage system described by the stochastic differential equation

$$
w \frac{d \zeta(t)}{d t}=\phi\left[x_{1}(t), x_{2}(t), \ldots, \zeta(t), t\right]
$$

where $\mathrm{x}_{\mathrm{m}}(t)$ are the components of a known multivariate stochastic process. In most practical cases $\mathrm{x}_{\mathrm{m}}(t)$ are interdependent, autocorrelated and seasonally distributed. In the relation (4) we have

$$
X_{1}(t)=Q(t) \quad ; \quad X_{2}(t)=D(t),
$$

and in (6), respectively,

$$
\begin{aligned}
& x_{1}(t)=\alpha_{0}(t) \quad ; \quad x_{2}(t)=\alpha_{1}(t) ; \\
& x_{3}(t)=\alpha_{2}(t) .
\end{aligned}
$$

Let us assume that the time is divided into intervals $\left(t_{0}, t_{1}\right)$, $\left(t_{1}, t_{2}\right)$, etc., and that for each of these intervals the random values

$$
\begin{gathered}
x_{m i}=x(t) \text { for } t_{i-1}<t<t_{i} \\
m=1,2, \ldots .
\end{gathered}
$$

are constants, i.e.

$$
\underline{x}_{i}=\left\langle x_{1 i}, x_{2 i}, \ldots x_{m i}, \ldots\right\rangle
$$

is a multivariate random variable with a given P.D.F. In some cases the conditional (forecasted) P.D.F. may be used.

If the solution of (15) exists, it can be expressed by the following relationship $\left(\tau_{i}=t_{i}-t_{i-1}\right)$ : 


$$
\Phi\left(\zeta_{i-1}, \zeta_{i}, x_{1 i}, x_{2 i}, \ldots, \tau_{i}\right)=0
$$

or sometimes in an explicit form,

$$
\zeta_{i}=\Phi\left(\zeta_{i-1}, x_{1 i}, x_{2 i}, \ldots, \tau_{i}\right)
$$

where $\zeta_{i}=\zeta\left(t_{i}\right)$ and $\zeta_{i-1}=\zeta\left(t_{i-1}\right)$. The process $\zeta_{i^{\prime}} i=0,1,2, \ldots$ is discrete-time and continuous-space, but for computational purposes it may be discretized also in the space domain.

Let us assume, as was done in [8] for the univariate case, that the total storage capacity $W$, constant or varying in time, is divided into $r$ intervals. The relative storage level will be said to be in the state $s_{\alpha}$ if

$$
\frac{\alpha-1}{r}<\zeta \leq \frac{\alpha}{r} \quad \alpha=1,2, \ldots, r .
$$

In the time intervals $\left(t_{i}, t_{i+1}\right)$ and $\left(t_{i-1}, t_{i}\right)$ the level of storage may move from $s_{\alpha}^{i-1}$ to $s_{\beta}^{i}$ and from $s_{\beta}^{i}$ to $s_{\gamma}^{i+1}$, as is shown in Figure 5. Given that the number $r$ of the storage states is sufficiently large, it seems feasible to assume that the transition from $s_{\alpha}^{i-1}$ to $s_{\beta}^{i}$ will occur if inequalities

$$
\frac{1}{r}(\beta-(\alpha-0,5))<\zeta_{i}-\zeta_{i-1} \leq \frac{1}{r}((\beta-1)-(\alpha-0,5))
$$

are fulfilled.

Let us now consider a class of release functions such that for given $\left(\xi_{i-1}=z_{i-1} ; \zeta_{i}=z_{i}\right)$ a unique functional relationship exists, namely 


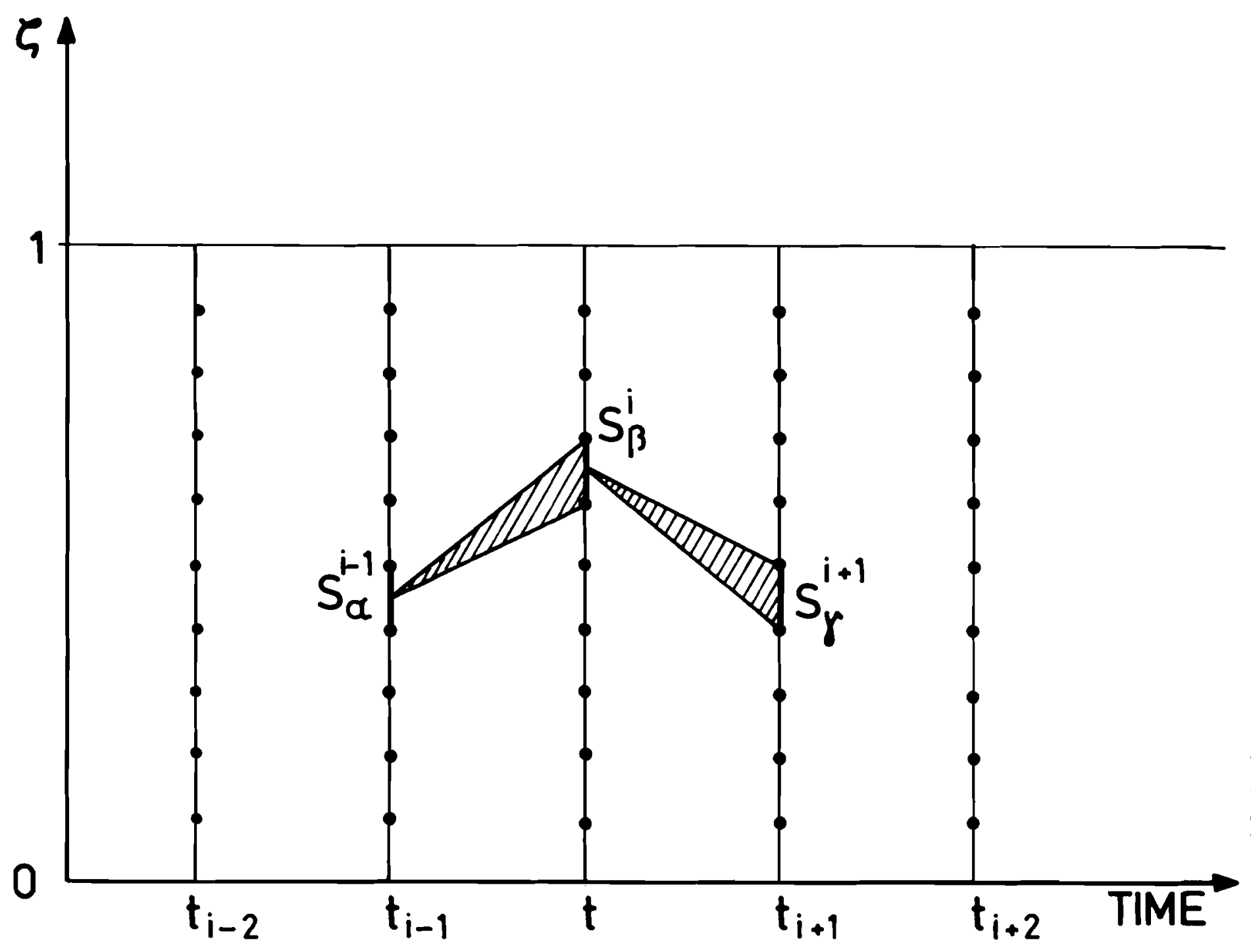

FIGURE 5.TRANSITION OF STORAGE STATES. 


$$
h_{z_{i-1}}, z_{i}\left(x_{1, i}, x_{2 ; i}, \ldots, x_{m, i}\right)=0 \text {, }
$$

and that for each system of inequalities (21) we may find a unique set $\Omega_{\alpha \beta}^{i}$ in the $\underline{x}_{i}$-space. An example of such sets related to the release function (2) and relation (12) is presented in Figure 6. Therefore we have

$$
P\left(s_{\alpha}^{i-1}+s_{\beta}^{i}\right)=P\left(\underline{x}_{i} \subset \Omega_{\alpha \beta}^{i-1}\right)
$$

and, respectively,

$$
P\left(s_{\beta}^{i}+s_{p}^{i+1} \mid s_{\alpha}^{i-1} \rightarrow s_{p}^{i}\right)=P\left(\underline{x}_{i+1} \subset \Omega_{\beta \gamma}^{i} \mid \underline{x}_{i} \subset \Omega_{\alpha \beta}^{i-1}\right)
$$

If the random vectors $\underline{x}_{1}, \underline{x}_{2}, \ldots, \underline{x}_{i}, \ldots$ form the multivariate, lag-one Markov process, then the combined storage level intervals

$$
\left(s^{0}, s^{1}\right),\left(s^{1}, s^{2}\right), \ldots,\left(s^{i-1} s^{i}\right),\left(s^{i} s^{i+1}\right)
$$

are the states of the Markovian process, and of course,

$$
\zeta_{0}, \zeta_{1}, \zeta_{2}, \ldots \zeta_{i-1}, \zeta_{i}
$$

is the lag-two, discrete-time, discrete-space Markov process.

Having the conditional (transition) probabilities (24) and some information on the initial state $s^{\circ}$ for $t=t_{0}$, we may easily find all the stochastic characteristics of the storage process (26). In particular, if $\mathrm{A}^{\mathrm{i}}$ is the matrix of probabilities (23) and $B^{i, i+1}$ is the matrix of conditional probabilities (24), then for each $i=1,2, \ldots$

$$
A^{i+1}=A_{B}^{i, i+1}
$$




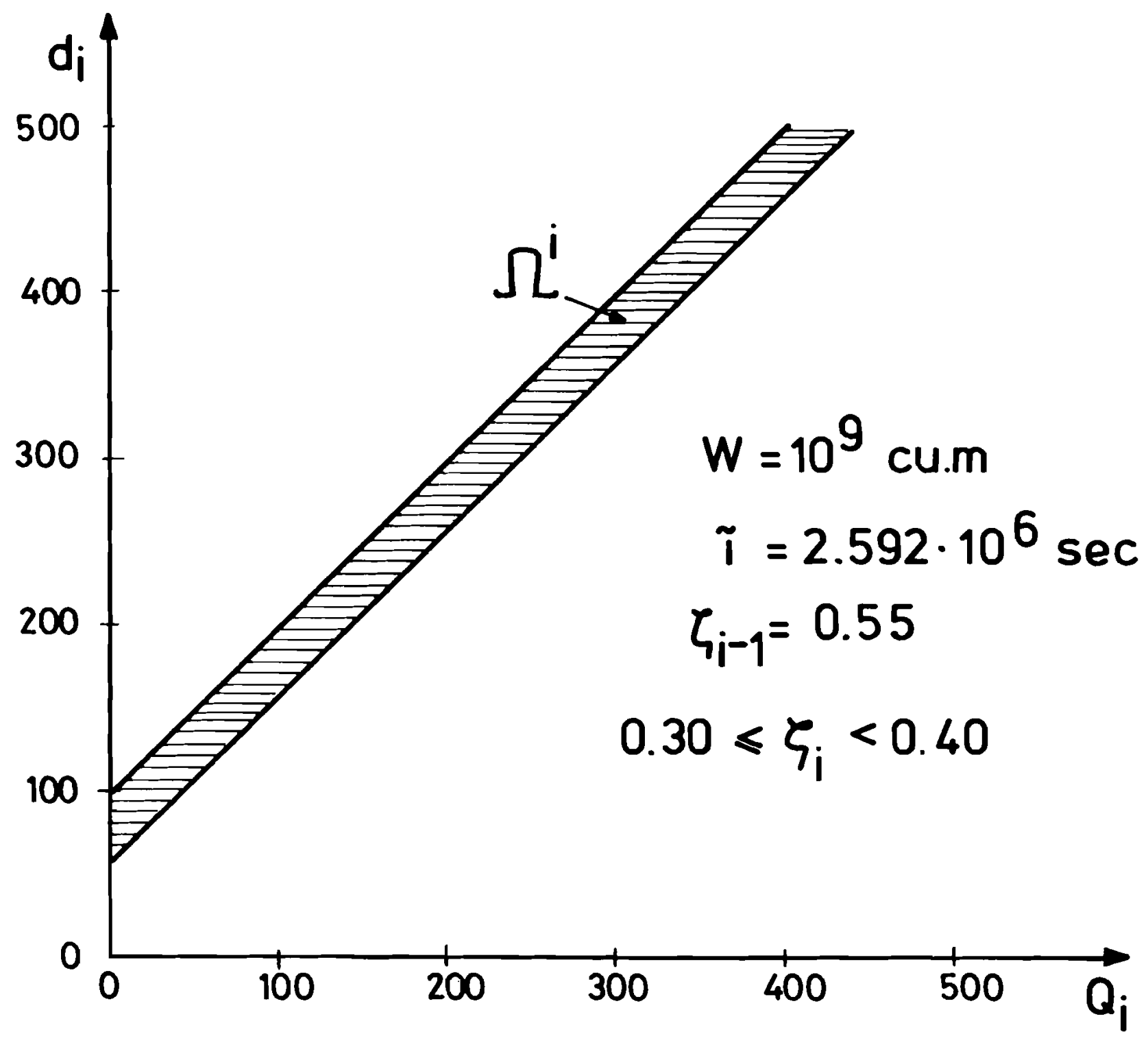

FIGURE 6. SET $\Omega^{i}\left(Q_{i}, d_{i}\right)$ CORRESPONDING TO

THE TRANSITION $\mathrm{S}^{i-1} \longrightarrow \mathrm{S}^{i}-$ AN EXAMPLE. 


$$
P s_{\beta}^{i}=\sum_{\alpha=1}^{r} P\left(s_{\alpha}^{i-1} \rightarrow s_{\beta}^{i}\right)
$$

Intuition suggests that in most practical cases water resources storage processes reach some sort of statistical equilibrium, which could be expressed by the periodic sets of ergodic probabilities. If such sets exist, they could be obtained from the system of 1 inear equations

$$
A_{\text {erg }}^{1}=A_{\text {erg }}^{1+k} \quad B=A_{\text {erg }}^{1} B
$$

which describe the simple fact that if the year is divided into $k$ intervals, then $A_{e r g}^{1+k}=A_{e r g}^{1}$. The matrix of transition probabilities is equal to

$$
\mathrm{B}=\mathrm{B}^{1,2} \cdot \mathrm{B}^{2,3} \cdot \ldots \mathrm{B}^{\mathrm{k}, 1+\mathrm{k}}
$$

The remaining matrices $A_{\text {erg }}^{i} i=2,3, \ldots, k$ may be found by using transformations similar to (27).

It should be pointed out that in most cases it will not be easy to find the sets $\Omega$ and to compute the transition probabilities. This may create problems in applications of the above procedure to practical water resources problems, and maybe the classical method of statistical experiments (Monte Carło approach) will be more convenient for solving such reservoir problems. Nevertheless, even the knowledge of the general structure of storage processes dependent on multivariate random inflow and outflow may give us valuable information. 
Acknowledgements

The author would like to thank Prof. A.A. Anis, Prof. E.H. Lloyd and Prof. V. Yevjevich for their interest and valuable comments. 


\section{References}

[1] Abramisvili, B.S. and R.I. Citasvili. O markovskich svoistvach rekurrentno sviazannych funkcii ot markovskich processov, diskretnoe vremia (in Russian), Trudy Inst. Prikl. Matem., Tbilisi, 1969.

[2] Anis, A.A. and E.H. Lloyd. On the Range of Partial Sums of a Finite Number of Independent Normal Variates, Biometrika, 40 (1953), pp. 35-42.

[3] Anis, A.A. and S.S. Daond. A Continuous Reservoir Storage Problem Involving Two Streams, J. Inst. Math. Applics., 6, 1970.

[4] Dooge, J.C.I. A General Theory of the Unit Hydrograph, Journ. Geophysical Research, 64 (1959), p. 241.

[5] Gani, I. Problems in the Probability Theory of storage Systems, J. Roy. Stat. Soc., B, 19, 1957.

[6] Jurak, D. Heat Exchange Coefficients for Cooling Lakes (to appear in Journ. of Hydrologic Sciences).

[7] Kaczmarek, z . Programowanie gospodarki zbiornikowej, Wyd. Politechniki Warszawskiej, 1960.

[8] Kaczmarek, z. Podstawy gospodarki zbiornikowej, (in Polish), Archiwum Hydrotechniki, X (1), 1963.

[9] Kaczmarek, Z. Modeli gidrologiczeskich proqnozov (in Russian), Vodnye resursy, Moskva, 1973.

[10] Kirby, W.H. Markov Chain Storage Models for Statistical Hydrology, Cornell University, Water Resources Center.

[11] Lloyd, E.H. A Probability Theory of Reservoirs with Serially Correlated Inputs, J. Hydrol., 1, 1963.

[12] Lloyd, E.H. Stochastic Reservoir Theory, Advances in Hydrosciences, IV, 1966.

[13] Mitosek, H.T. Optymalizacja stochastycznych modeli retencjonowania podanych przez P.A.P. Morana $i$ z. Kaczmarek, (in Polish), Archiwum Hydrotechniki, $\mathrm{XX}(3), 1973$.

[14] Moran, P.A.P. A Probability Theory of Dams and Storage Systems, Austr. J. Appl. Sci., 5, 1954. 
[15] Moran, P.A.P. The Theory of Storage, Methuen, London, 1959.

[16] Nash, I.E. A Unit Hydrograph Study with particular Reference to British Catchments, Inst. Civ. Eng. Proc., 17, 1960 .

[17] Prabhu, N.V. Time-Dependent Results in Storage Theory, Methuen, London, 1964.

[18] Rozanov, Yu. A. Statistical Equilibrium of Processes in Dam Storage, I.I.A.S.A. Research Report 75-4.

[19] Yevjevich, V. The Application of Surplus, Deficit and Range in Hydrology, Hydrol. Pap., 10, Colorado State University, 1965 . 